\title{
Changes in lipid composition and arachidonic acid turnover during the life cycle of the yeast Dipodascopsis uninucleata
}

\author{
J. LODEWyK F. KocK* and Colin Ratledge \\ Department of Applied Biology, University of Hull, Hull HU6 7RX, UK
}

(Received 10 August 1992; revised 15 October 1992; accepted 29 October 1992)

\begin{abstract}
Ungerminated ascospores of Dipodascopsis uninucleata contained 18 times more lipid (5.5\% dry wt) than germinated cells; the lipid comprised $58 \%(w / w)$ glycolipids, $28 \%(w / w)$ neutral lipids (mainly triacylglycerols) and $14 \%(w / w)$ phospholipids (mainly phosphatidylcholine and phosphatidylethanolamine). During germination the absolute amounts of all three lipid fractions fell sharply but, during the subsequent initiation of hyphal growth, the amount of phospholipids increased. As these hyphae began to differentiate for the sexual stage of the life cycle, the amount of neutral lipid then increased. The fatty acyl groups of the glyco-, neutral and phospholipid fractions throughout the life cycle were mainly palmitate (16:0), oleate (18:1) and linoleate (18:2). The percentage of 16:0 remained constant during the life cycle while the relative amounts of 18:2 plus $\alpha$-linolenate (18:3) in the glyco-, neutral and phospholipid fractions first increased during initiation of growth and then decreased during the onset of differentiation. The opposite trend occurred with 18:1. When $\left[{ }^{3} \mathrm{H}\right]$ arachidonic acid (ARA) and $\left[1-{ }^{14} \mathrm{C}\right] 18: 1$ were fed separately to $D$. uninucleata, both were rapidly incorporated into phospholipids. Highest incorporation of ARA was in the growth phase; during the onset and remainder of the differentiation phase, the amount of ARA decreased in this fraction. Incorporation of 18:1 increased during growth and differentiation, with a significant proportion (49\% to $57 \%$ ) being incorporated into triacylglycerols compared to a much smaller proportion (12\% to $17 \%)$ of ARA.
\end{abstract}

\section{Introduction}

The presence of two isomers of $\alpha$-pentanor prostaglandin $\mathrm{F}_{2 \alpha}-\gamma$-lactone (Kock et al., 1991) together with a 3hydroxyeicosatetraenoic acid in the yeast Dipodascopsis uninucleata (Van Dyk et al., 1991) has suggested that an arachidonic acid (ARA) cascade may be present. Such a cascade, from which numerous metabolites could be produced, would be similar to that which occurs in animals for the biosynthesis of prostaglandins, leukotrienes and thromboxanes from eicosatrienoic acid, ARA and eicosapentaenoic acids. These products are a group of pharmacologically potent compounds which currently find application in medicine in inducing labour and

\footnotetext{
* Author for correspondence: Department of Microbiology and Biochemistry, University of the OFS, PO Box 339, Bloemfontein 9300, South Africa. Tel. (051) 4012396; fax (051) 474152.

Abbreviations: ARA, arachidonic acid; 16:0, palmitic acid; 16:1, palmitoleic acid; 18:0, stearic acid; $18: 1$, oleic acid; $18: 2$, linoleic acid; 18:3, linolenic acid; PUFA, polyunsaturated fatty acid; TEA, triethylamine; TAG, triacylglycerol.
}

inhibiting blood platelet aggregation (Slater \& McDonald-Gibson, 1987). These compounds are extremely expensive since they are produced by complex chemical synthesis. Consequently, a natural source, such as yeasts, from which these hormones could be prepared at a lower cost, would be beneficial.

With this in mind, we have investigated the lipid composition and ARA turnover during the life cycle of $D$. uninucleata in order eventually to optimize the production of these compounds. The life cycle of $D$. uninucleata has been described elsewhere (Botha et al., 1992), but an outline is given in the Results and Discussion section.

\section{Methods}

Strain used. D. uninucleata UOFS Y128 was used throughout the study and is held at the University of the Orange Free State, Bloemfontein, South Africa.

Cultivation and harvesting of cells. D. uninucleata was cultivated from agar slants in eight 1 -litre conical flasks at $30^{\circ} \mathrm{C}$ (shaken at 145 r.p.m.) until ascospores were liberated-i.e. after about $46 \mathrm{~h}$. Each flask contained $400 \mathrm{ml}$ YM medium $(8 \mathrm{~g}$ glucose, $1.2 \mathrm{~g}$ malt extract, $1.2 \mathrm{~g}$ yeast extract and $2 \mathrm{~g}$ peptone per $400 \mathrm{ml}$ ). Ascospores were separated 
by the method described by Botha et al. (1992). To obtain synchronized cultures, a fraction of the ascospores (the remainder was freeze-dried) was reinoculated into eight 1 -litre conical flasks, each containing $400 \mathrm{ml} \mathrm{YM}$ medium, to give about $5 \times 10^{5}$ ascospores $\mathrm{ml}^{-1}$. These cultures were grown as described above. Samples (i.e. two flasks at a time) were taken after $20,24,30$ and $46 \mathrm{~h}$. These were centrifuged at $8000 \mathrm{~g}$ for $20 \mathrm{~min}$, washed three times with distilled water and finally freeze-dried. Culture biomass, expressed as $\mathrm{mg}$ dry weight $\mathrm{ml}^{-1}$, was determined throughout the life cycle by filtration of $2 \mathrm{ml}$ of culture through a preweighed membrane filter $(0.22 \mu \mathrm{m}$ pore size $)$, washed with distilled water $(2 \times 2 \mathrm{ml})$ and dried to a constant weight at $110^{\circ} \mathrm{C}$. This procedure was performed in triplicate.

Lipid extraction. This was performed on freeze-dried material as described by Kendrick \& Ratledge (1992) and included extraction with chloroform/methanol $(2: 1, \mathrm{v} / \mathrm{v})$ as described by Folch et al. (1957), three washes with distilled water and final evaporation of the organic phase. Lipid material was finally dissolved in a minimal volume of diethyl ether and transferred to preweighed vials. For determination of lipid weights, samples were dried to constant weight in a vacuum oven at $50^{\circ} \mathrm{C}$ over $\mathrm{P}_{2} \mathrm{O}_{5}$.

Fractionation of extracted lipid. Extracted lipid was dissolved in chloroform and applied to a column $(140 \mathrm{~mm} \times 20 \mathrm{~mm})$ of activated (by heating overnight at $110^{\circ} \mathrm{C}$ ) silicic acid. Neutral, sphingo- and glycolipids (as a combined fraction), as well as polar lipids, were eluted by successive applications of organic solvents as described by Kendrick \& Ratledge (1992). Final solvent removal and storage was as for whole lipid extracts. Each fraction was then purified further by TLC.

Thin-layer chromatography. TLC of the neutral, sphingo- and glycolipid fraction was on silica gel thin-layer plates backed with aluminium (Merck). The polar fraction, containing phospholipids, was separated using chloroform/methanol/water/acetic acid $(65: 43: 3: 1$, by vol.).

The neutral lipid fraction was separated using petroleum ether (b.p. 60 to $\left.80^{\circ} \mathrm{C}\right) /$ diethyl ether/acetic acid $(85: 15: 1$, by vol.). The combined sphingo- and glycolipid fraction was separated using chloroform/ methanol $/ \mathrm{NH}_{4} \mathrm{OH}$, sp. gr. $0 \cdot 880(80: 20: 0 \cdot 2$, by vol.). Plates were developed one-dimensionally by the ascending technique and visualized by exposure to $I_{2}$ vapour. Phospholipids were further visualized by staining with Dragendorff reagent, which specifically stains cholinecontaining lipids, with ninhydrin for the detection of lipids with free amino groups (Higgins, 1987), and with a molybdenum blue reagent spray for the detection of phospholipids in general by staining phosphate-containing lipids (Dittmer \& Lester, 1964). Glycolipids were visualized by spraying with $\alpha$-naphthol solution (Higgins, 1987). Further identification was achieved by running suitable authentic standards along experimental samples.

Fatty acid analysis. Lipid was dissolved in chloroform and methylated by the addition of trimethyl sulphonium hydroxide (TMSH) as described by Butte (1983).

The fatty acid methyl esters were analysed using a Philips PU 4500 gas chromatograph and a $10 \%$ diethylene glycol succinate column $(2 \mathrm{~m} \times 4 \mathrm{~mm})$ as described by Kendrick \& Ratledge (1992). Peaks were identified by reference to authentic standards.

Addition of $\left[{ }^{3} \mathrm{H}\right] \mathrm{ARA}$ and $\left[1-{ }^{14} \mathrm{C}\right] 18: 1$. D. uninucleata was cultivated from about $5 \times 10^{5}$ ascospores (ml medium) ${ }^{-1}$ in $250 \mathrm{ml}$ conical flasks (containing $40 \mathrm{ml} \mathrm{YM}$ medium) for $46 \mathrm{~h}$ at $30^{\circ} \mathrm{C}$ with shaking at 160 r.p.m. At the start of cultivation, $10 \mu \mathrm{l}$ containing $10 \mu \mathrm{Ci}$ $\left[5,6,8,9,11,12,14,15-{ }^{3} \mathrm{H}\right] \mathrm{ARA} \quad\left(219 \mathrm{Ci} \mathrm{mmol}^{-1} ; 8 \cdot 10 \mathrm{TBq} \mathrm{mmol}^{-1}\right)$ in ethanol was added. The cells ( $4 \mathrm{ml}$ culture) were harvested periodically by membrane filtration $(0.22 \mu \mathrm{m})$, frozen immediately and then freezedried. This experiment was repeated with the addition of $\left[{ }^{3} \mathrm{H}\right] \mathrm{ARA}$ $(10 \mu \mathrm{Ci})$ to about $1.01 \times 10^{6}$ ascospores (ml culture) ${ }^{-1}$ in $\mathrm{YM}$ and repeated with the addition of $\left[{ }^{3} \mathrm{H}\right] \mathrm{ARA}$ and unlabelled ARA $(10 \mu \mathrm{Ci}$, $0.2 \mu \mathrm{mol}$ ) to about $5 \times 10^{5}$ ascospores ( $\mathrm{ml}$ culture) ${ }^{-1}$ in YM. This experiment was also repeated in duplicate with the addition of $\left[1-{ }^{14} \mathrm{C}\right] 18: 1\left(52.7 \mathrm{mCi} \mathrm{mmol}^{-1} ; 1.95 \mathrm{GBq} \mathrm{mmol}^{-1}\right)$ to a culture containing about $5 \times 10^{5}$ ascospores $\mathrm{ml}^{-1}$.

To determine the incorporation of $\left[{ }^{3} \mathrm{H}\right] \mathrm{ARA}$ when fed at the start of the differentiation phase, the previous experiment was repeated with [ ${ }^{3} \mathrm{H}$ ]ARA $(10 \mu \mathrm{Ci})$ added after $30 \mathrm{~h}$ incubation to about $5 \times 10^{5}$ ascospores (ml culture) $)^{-1}$. Samples were taken after $31,36,46$ and $54 \mathrm{~h}$. This experiment was repeated twice.

Lipid extraction of yeast. This was performed as described above. Lyophilized filters with cells were extracted overnight at ambient temperature with $6 \mathrm{ml}$ chloroform/methanol $(2: 1, \mathrm{v} / \mathrm{v})$. The filtrate was washed three times with $1 \mathrm{ml}$ distilled $\mathrm{H}_{2} \mathrm{O}$, divided into three equal volumes and then evaporated to dryness under a stream of $\mathrm{N}_{2}$. The samples were stored at $-20^{\circ} \mathrm{C}$ under a blanket of $\mathrm{N}_{2}$.

Thin-layer chromatography of lipid extracts. Each sample was resuspended in ethyl acetate and run on silica gel thin-layer plates. Neutral, sphingo-, glyco- and phospholipids were separated and visualized as described above. In addition, samples, pre-treated with triethylamine (TEA) in ethyl acetate $(20 \%, v / v$, TEA suspension) were separated using ethyl acetate/methanol/water/TEA $(160: 3: 100: 1$, by vol.) for the detection of TEA salts, which should include ARA and ARA metabolites not esterified to other compounds. Suitable lipid standards were run alongside experimental samples.

Radioactive scans. TLC plates were scanned for radioactivity by the Bioscan Imaging Scanner System 200-IBM coupled to the Bioscan Auto Changer 4000 and integrater.

Chemicals. All organic solvents and chemicals used were of analytical reagent grade and obtained from major retailers. Silicic acid (100 mesh) was from Aldrich. Glyco-, sphingo-, neutral and phospholipid standards, as well as fatty acid standards, were from Sigma. $\left[5,6,8,9.11,12,14,15-{ }^{3} \mathrm{H}\right] \mathrm{ARA}$ (sp. act. $219 \mathrm{Ci} \mathrm{mmol}^{-1}$ ) and $\left[1-{ }^{14} \mathrm{C}\right] 18: 1$ $\left(52.7 \mathrm{mCi} \mathrm{mmol}^{-1}\right)$ were from Amersham.

\section{Results and Discussion}

\section{Changes in total lipid content during the life cycle}

A single life cycle of $D$. uninucleat $a$ is characterized by an asexual and a sexual or differentiation phase. The asexual phase is initiated by the germination of ascospores into hyphae. The differentiation phase includes plasmogamy of two gametangia, karyogamy, meiosis and eventually ascosporogenesis in relatively large sac-like asci (Botha et al., 1992). When ascospores are cultivated in a suitable medium, as described in Methods, the asexual and sexual phases can be clearly distinguished. During the first $20 \mathrm{~h}$, the small reniform ascospores swell considerably, followed by the formation of a germ tube and an increase in dry weight (Table 1). At about $24 \mathrm{~h}$, the formation of hyphae occurs. This is referred to as the growth phase and is characterized by a further increase in dry weight (Table 1). At approximately $30 \mathrm{~h}$, the differentiation or sexual stage proceeds, and under our conditions it was completed within about $46 \mathrm{~h}$ of the start of incubation, when ascospores were liberated from asci. A further increase in dry weight, mainly caused by the formation of 
Table 1. Changes in lipid content, dry weight, lipid fractions and esterified fatty acids over one complete life cycle of D. uninucleata

\begin{tabular}{|c|c|c|c|c|c|c|c|c|c|c|c|c|}
\hline \multirow{2}{*}{$\begin{array}{l}\text { Time } \\
\text { (h) }\end{array}$} & \multirow{2}{*}{$\begin{array}{l}\text { Stage of } \\
\text { life cycle* }\end{array}$} & \multirow{2}{*}{$\begin{array}{l}\text { Dry } \\
\text { wt } \dagger\end{array}$} & \multirow{2}{*}{$\begin{array}{c}\text { Lipid } \\
\text { content } \ddagger\end{array}$} & \multicolumn{3}{|c|}{ Lipid fractions $(\%) \S$} & \multicolumn{3}{|c|}{ Oleic acid $(\%) \|$} & \multicolumn{3}{|c|}{ PUFAs (\%)\| } \\
\hline & & & & PL & NL & GL & PL & NL & GL & PL & $\mathrm{NL}$ & GL \\
\hline 0 & A & 0.2 & $55 \cdot 0$ & $14 \cdot 0$ & $28 \cdot 0$ & $58 \cdot 0$ & $43 \cdot 5$ & $42 \cdot 5$ & 46.5 & $25 \cdot 0$ & $20 \cdot 5$ & $18 \cdot 0$ \\
\hline 20 & B & 0.4 & $3 \cdot 3$ & 27.5 & $12 \cdot 5$ & 60.0 & $25 \cdot 0$ & $30 \cdot 0$ & $23 \cdot 0$ & 44.0 & $35 \cdot 5$ & $41 \cdot 0$ \\
\hline 24 & C & 0.8 & $7 \cdot 2$ & 52.5 & 13.5 & 34.0 & $28 \cdot 5$ & 34.5 & $25 \cdot 5$ & 37.5 & 31.0 & 34.0 \\
\hline 30 & D & 1.6 & $3 \cdot 4$ & $40 \cdot 0$ & $32 \cdot 0$ & $28 \cdot 0$ & $34 \cdot 0$ & $35 \cdot 5$ & $32 \cdot 5$ & $31 \cdot 0$ & $21 \cdot 0$ & $28 \cdot 0$ \\
\hline 46 & E & 3.5 & $12 \cdot 0$ & $25 \cdot 5$ & $42 \cdot 0$ & 32.5 & $48 \cdot 5$ & $46 \cdot 0$ & $47 \cdot 5$ & $27 \cdot 0$ & $19 \cdot 0$ & $17 \cdot 5$ \\
\hline
\end{tabular}

* A, ascospores; B, germination; C, hyphae formation; D, plasmogamy; E, ascospore liberation.

$\dagger$ Given as $\mathrm{mg}$ ( $\mathrm{ml}$ culture $)^{-1}$; mean of three repetitions ( $\mathrm{SE}<5 \%$ of the mean).

$\ddagger$ Given as mg (g dry wt $)^{-1}$; mean of two repetitions.

$\S \mathrm{PL}$, phospholipid fraction; NL, neutral lipid fraction; GL, glycolipid fraction.

| Percentages of oleic acid (i.e. 18:1) and PUFAs (i.e. 18:2 and 18:3) esterified to lipid fractions.

asci, was observed (Table 1). These results are in accordance with those of Botha et al. (1992).

Table 1 also shows changes in total lipid content of $D$. uninucleata over one complete life cycle. The efficiency of the lipid extraction method (Folch et al., 1957) was evaluated by re-extracting already extracted samples. It was found that $94.1 \% \pm 5.0 \%(\mathrm{w} / \mathrm{w})$ of total extractable lipid had been initially extracted from samples taken during different stages in the life cycle (mean of five determinations, $\pm \mathrm{SE}$ ).

In ungerminated ascospores (time $0 \mathrm{~h}$ ), total lipid accounted for $55 \mathrm{mg}(\mathrm{g} \text { dry wt })^{-1}$ or $5.5 \%(\mathrm{w} / \mathrm{w})$. This total lipid level was higher than that found for any of the other developmental stages. Upon germination $(20 \mathrm{~h})$, the total lipid content decreased significantly to only $0.33 \%(\mathrm{w} / \mathrm{w})$. During mycelial elongation and elaboration $(24 \mathrm{~h})$, the total lipid content remained low $(0.72 \%, w / w)$. This stage is characterized by a significant increase in dry weight. As the yeast entered the differentiation phase $(30 \mathrm{~h})$, the lipid content was still low $(0.34 \%, \mathrm{w} / \mathrm{w})$ but it increased to $1.2 \%(\mathrm{w} / \mathrm{w})$ towards the end of the life cycle $(46 \mathrm{~h})$, probably reflecting the production of lipid-rich ascospores. These results show that changes in lipid content are greatest during germination; during differentiation not much variation occurs. Similar patterns have been reported during the development of Achlya (Law \& Burton, 1976a).

\section{Composition of total lipid throughout the life cycle}

Total lipid extracted from cells during different stages of development was fractionated into three classes by column chromatography on silicic acid (see Methods); the results are shown in Table 1 . No contamination between fractions was detected in any of the samples analysed. On average, $86 \%(\mathrm{w} / \mathrm{w})$ of total extractable lipid was recovered from silicic acid column chromatography. Subsequent TLC analyses of the neutral lipid fraction showed the majority of lipid within this fraction to be triacylglycerol (TAG), with very small proportions of diacylglycerol and monoacylglycerol.

The polar lipid fractions contained only phospholipids as determined by TLC. Detailed TLC analyses of phospholipids showed the presence of mainly phosphatidylcholine and phosphatidylethanolamine. Three or four components were identified as glycolipids from their reaction with $\alpha$-naphthol spray reagent. One of these components had the same $R_{F}$ value as galactosyldiacylglycerol in TLC analyses.

The percentage of neutral lipid in the ascospores $(0 \mathrm{~h})$ decreased upon germination $(20 \mathrm{~h})$ to a minimum followed by an increase towards the end of the life cycle $(46 \mathrm{~h})$. In the ascospores, the proportion of total lipid represented by phospholipid was lower than that contributed by the neutral and glycolipid fractions. The percentage of phospholipids increased upon germination $(20 \mathrm{~h})$ and during the initial stages of vegetative growth $(24 \mathrm{~h})$. During the differentiation phase ( 30 to $46 \mathrm{~h}$ ) the phospholipid fraction, as a percentage of the total lipid, declined. The demand for phospholipid for cell growth and membrane development would be expected to be maximal during the initial stages of growth, which may explain the increase in the percentage of phospholipids at this stage. Similar changes in phospholipid concentrations have been reported by Smith \& Silverman (1973) in Blastocladiella emersoni and by Law \& Burton $(1976 a)$ in Achlya.

It is interesting that during the first $20 \mathrm{~h}$, the glycolipid fraction comprised the largest fraction ( 58 to $60 \%, \mathrm{w} / \mathrm{w}$ ) of the total lipid. This fraction decreased on initiation of growth and remained constant during the rest of the life cycle. These results are consistent with those of Smith \& Silverman (1973) but at variance with the findings of Law \& Burton (1976b), who reported that the glycolipid fraction remained relatively low (10 to $20 \%$, w/w, of total lipid) throughout the development of Achlya sp. 


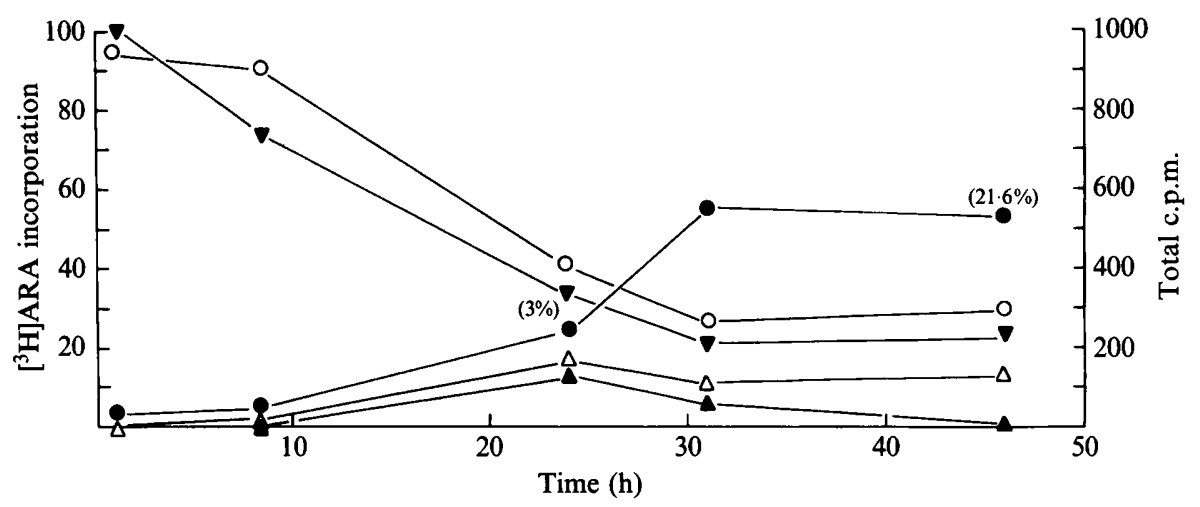

Fig. 1. Percentage $\left[{ }^{3} \mathrm{H}\right] \mathrm{ARA}$ incorporation during one complete life cycle (inoculum $=5.01 \times 10^{5}$ ascospores $\mathrm{ml}^{-1}$ ). $\mathrm{O},\left[{ }^{3} \mathrm{H}\right] \mathrm{ARA} ; \boldsymbol{\nabla}$, total ${ }^{3} \mathrm{H}$ c.p.m.; $\triangle$, TAG; $\boldsymbol{\Delta}$, phospholipids; $\boldsymbol{O}$, unknown lipid compounds (complex X). Percentages of non-esterified ARA metabolites in unknown lipid compounds are indicated in parentheses. See text for explanation.

The proportions of total lipid represented by glyco-, neutral and phospholipids in the ascospores are not reflected in cell material at the end of the life cycle, probably due to the very small proportion of ascospores present in hyphal material.

\section{Fatty acyl composition of lipids}

The changes in lipid content and composition, especially phospholipids, observed during the life cycle of $D$. uninucleata prompted an investigation into the fatty acyl composition of the glyco-, neutral and phospholipid fractions during the life cycle. All fractions contained $16: 0,16: 1,18: 0,18: 1,18: 2$ and $18: 3$. Only $18: 1,18: 2$ and $18: 3$ showed significant changes during the life cycle (Table 1).

At all stages of the life cycle, polyunsaturated fatty acids (PUFAs) were more abundant in the phospholipid fraction than in any other. The percentage of PUFAs in all three fractions increased during germination but then decreased towards the start of the differentiation phase and remained at this lower level to the end of the life cycle. The opposite trend was found for the percentage of 18:1 present in the three fractions: it decreased towards the germination phase and then increased towards the end of the life cycle. The demand for PUFAs seems to be higher during growth, while $18: 1$ is mainly required at the end of the life cycle.

\section{Arachidonic acid utilization during the life cycle}

Since it has been demonstrated that ARA is transformed to ARA cascade products in D. uninucleata (Kock et al., 1991), we decided to determine the fate of ARA in the life cycle of this yeast. These results should shed more light on the metabolism of ARA and may be helpful in future optimization studies for the production of eicosanoids.
Figs 1 and 2 illustrate the turnover of $\left[{ }^{3} \mathrm{H}\right]$ ARA during different development stages in the life cycle of $D$. uninucleata.

When $10 \mu \mathrm{Ci}\left[{ }^{3} \mathrm{H}\right] \mathrm{ARA}$ was fed to $5.01 \times 10^{5}$ ascospores (ml medium) $)^{-1}$, more than $90 \%$ of the labelled ARA was taken up by ascospores within $1 \mathrm{~h}$ of cultivation. A general decrease in both free $\left[{ }^{3} \mathrm{H}\right] \mathrm{ARA}$ and total ${ }^{3} \mathrm{H}$ was observed in cells during the germination and growth phases (i.e. 0 to $31 \mathrm{~h}$ : Fig. 1). These remained constant during the differentiation phase (i.e. 31 to $46 \mathrm{~h}$ ). The decrease in ${ }^{3} \mathrm{H}$ in the total lipid may be due to the transformation of $\left[{ }^{3} \mathrm{H}\right] \mathrm{ARA}$ into metabolites which are not extractable with chloroform/methanol.

During ascospore germination and initial growth (i.e. 0 to $24 \mathrm{~h}$ ), the total $\left[{ }^{3} \mathrm{H}\right]$ and $\left[{ }^{3} \mathrm{H}\right] \mathrm{ARA}$ content of the cells sharply decreased while lipid components such as phospholipids (including phosphatidylcholine and phosphatidylethanolamine), TAG and other lipid components (i.e. complex $\mathrm{X}$ ) became radioactive. [Complex $\mathrm{X}$ comprises labelled components which could not be positively identified by TLC using solvent systems for neutral and phospholipid separations. Also included in this fraction are non-esterified ARA metabolites which produced salts as determined by TLC in the presence of TEA dissolved in ethyl acetate. These were determined by subtracting the amounts of labelled ARA and labelled phospholipid as determined by neutral lipid and phospholipid separations, respectively, from the total amount of labelled compounds detected at the origin of the TLC which were separated by ethyl acetate/ methanol/water/TEA.] These results indicate that [ $\left.{ }^{3} \mathrm{H}\right] A R A$ is both incorporated into lipid and transformed into various metabolites.

During the start of the differentiation phase (i.e. $30 \mathrm{~h}$ ), the ${ }^{3} \mathrm{H}$-labelled phospholipid decreased, and it disappeared completely after maturation of asci (after $46 \mathrm{~h}$ ). These results coincide with the respective increase and 


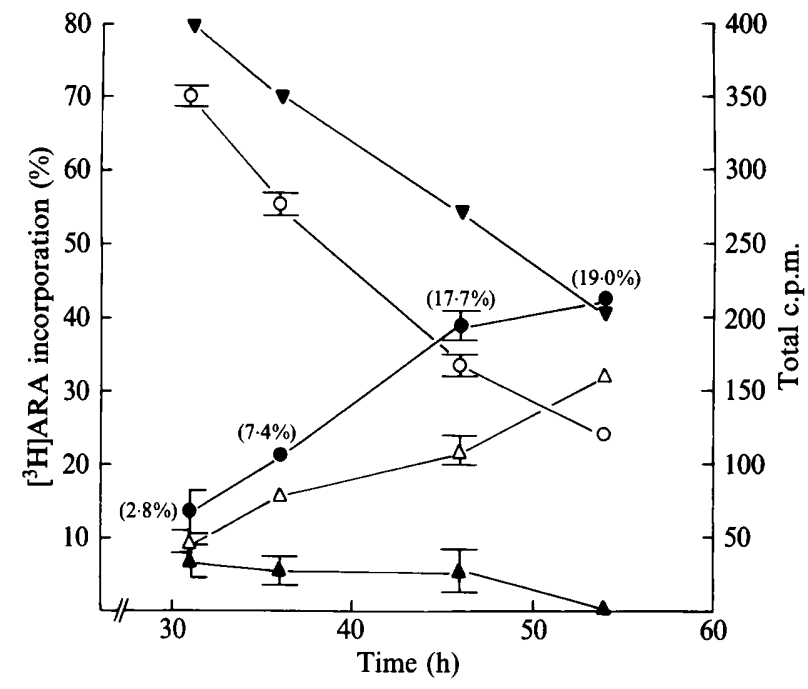

Fig. 2. Percentage $\left[{ }^{3} \mathrm{H}\right] A$ RA incorporation during the sexual reproductive (differentiation) phase (inoculum $=5.0 \times 10^{5}$ ascospores $\mathrm{ml}^{-1}$ ). O, $\left[{ }^{3} \mathrm{H}\right]$ ARA; $\boldsymbol{\nabla}$, total ${ }^{3} \mathrm{H}$ c.p.m.; $\triangle$, TAG; $\Delta$, phospholipids; - unknown lipid compounds (complex X). Percentages of nonesterified ARA metabolites in unknown lipid compounds are indicated in parentheses. See text for explanation. The bars represent the range of two repetitions.

decrease in percentage phospholipids observed during initial growth and differentiation (Table 1).

The disappearance of labelled phospholipids is probably partly due to the release of esterified $\left[{ }^{3} \mathrm{H}\right] \mathrm{ARA}$ by phospholipase activity. Radioactivity in the TAG fraction remained constant during the differentiation phase, as was the case with complex X, labelled free ARA and total chloroform-soluble ${ }^{3} \mathrm{H}$, which may indicate a cessation in metabolic activity concerning these compounds.

Similar patterns were obtained when $10 \mu \mathrm{Ci}\left[{ }^{3} \mathrm{H}\right] \mathrm{ARA}$ $(0.46 \mathrm{pmol})$ was added to $40 \mathrm{ml}$ of a suspension of $1.1 \times 10^{6}$ ascospores (ml culture) ${ }^{-1}$ at the start of the life cycle and when $10 \mu \mathrm{Ci}\left[{ }^{3} \mathrm{H}\right] \mathrm{ARA}(0.2 \mu \mathrm{mol})$ was fed to $40 \mathrm{ml}$ of a suspension of $5 \times 10^{5}$ ascospores (ml culture) ${ }^{-1}$ (results not shown).

When [ $\left.{ }^{3} \mathrm{H}\right] \mathrm{ARA}$ was fed at the start of the differentiation phase (Fig. 2), a general decrease in both $\left[{ }^{3} \mathrm{H}\right] \mathrm{ARA}$ and total ${ }^{3} \mathrm{H}$ was observed throughout the differentiation phase. Within $1 \mathrm{~h},\left[{ }^{3} \mathrm{H}\right]$ ARA was associated with phospholipids, triacylglycerols and complex X. During maturation of asci ( 31 to $46 \mathrm{~h}$ ), characterized by a large increase in the size of asci, degradation and further transformation of $\left[{ }^{3} \mathrm{H}\right] \mathrm{ARA}$ into complex $X$ was observed. The amount of $\left[{ }^{3} \mathrm{H}\right]$ ARA incorporated into phospholipids decreased during differentiation, supporting the results shown in Fig. 1.

Although the relative percentage of TAG increased during this phase ( 36 to $46 \mathrm{~h}$ ), this was in balance with
Table 2. Percentage $\left[1-{ }^{14} \mathrm{C}\right] 18: 1$ incorporation during one complete life cycle of $D$. uninucleata

\begin{tabular}{|c|c|c|c|c|c|c|}
\hline \multirow{2}{*}{$\begin{array}{l}\text { Time } \\
\text { (h) }\end{array}$} & \multirow{2}{*}{$\begin{array}{l}\text { Stage of } \\
\text { life cycle* }\end{array}$} & \multicolumn{3}{|c|}{$\begin{array}{c}\text { Percentage } \\
{\left[1-{ }^{14} \mathrm{C}\right] 18: 1} \\
\text { incorporation } \dagger\end{array}$} & \multirow{2}{*}{$\begin{array}{c}\text { Percentage } \\
{\left[1-{ }^{14} \mathrm{C}\right] 18: 1} \\
\text { (residual) }\end{array}$} & \multirow{2}{*}{$\begin{array}{l}\text { Total } \\
\text { c.p.m. }\end{array}$} \\
\hline & & PL & TAG & $X_{\ddagger} \ddagger$ & & \\
\hline 1 & A & 0.0 & 0.0 & 0.0 & 99.0 & 21500 \\
\hline 24 & $\mathrm{C}$ & $10 \cdot 0$ & $57 \cdot 0$ & $19 \cdot 5(1.0)$ & $13 \cdot 0$ & 14500 \\
\hline 46 & E & 18.5 & $49 \cdot 0$ & $13 \cdot 5(5 \cdot 6)$ & $18 \cdot 0$ & 11250 \\
\hline
\end{tabular}

*A, ascospores; C, hyphae formation; E, ascospore liberation.

† Percentage $\left[1-{ }^{14} \mathrm{C}\right]$ oleic acid incorporation into phospholipids (PL), triacylglycerol (TAG) and complex X. Numbers in parentheses indicate the percentage of non-esterified 18:1 metabolites included in complex $\mathrm{X}$ which produced salts in the presence of TEA.

$\$$ Lipid compounds of complex $\mathrm{X}$ are explained in the text.

the decrease in total ${ }^{3} \mathrm{H}$, resulting in constant amounts of labelled TAG being formed during this stage, which is in agreement with the results shown in Fig. 1. When the majority of asci released their ascospores (i.e. after $54 \mathrm{~h}$ ), a further increase in labelled complex $X$ and a decrease in labelled phospholipids, free $\left[{ }^{3} \mathrm{H}\right] \mathrm{ARA}$ and total counts was observed.

To determine if other fatty acids are metabolized similarly to ARA, $\left[1-{ }^{14} \mathrm{C}\right] 18: 1(10 \mu \mathrm{Ci}, 0 \cdot 2 \mu \mathrm{mol})$, a major fatty acid in D. uninucleata, was fed to $5.0 \times 10^{5}$ ascospores (ml medium) ${ }^{-1}$. The results are shown in Table 2. As was found with ARA, the content of $\left[1-{ }^{14} \mathrm{C}\right] 18: 1$ and total lipid ${ }^{14} \mathrm{C}$ decreased as the life cycle progressed. Most of the labelled 18:1 (57\%) was incorporated into TAG during the initial growth phase, compared to only $17 \%$ for $\left[{ }^{3} \mathrm{H}\right] \mathrm{ARA}$ (Fig. 1). No decrease in radioactive phospholipids (mainly phosphatidylcholine and phosphatidylethanolamine), as was the case in $\left[{ }^{3} \mathrm{H}\right] \mathrm{ARA}$ experiments, was found during the differentiation phase. The percentage of $\left[1-{ }^{14} \mathrm{C}\right] 18: 1$ incorporated into phospholipids increased towards the end of the life cycle, which is similar to the increase in percentage 18:1 found in the unlabelled phospholipid fraction during growth and differentiation (Table 1). Labelled complex $\mathbf{X}$ reached a maximum during growth and declined slightly towards the end of the life cycle.

The percentage of $\left[{ }^{3} \mathrm{H}\right] \mathrm{ARA}$ metabolites capable of producing TEA salts, and associated with complex $\mathrm{X}$, increased during differentiation when $\left[{ }^{3} \mathrm{H}\right] \mathrm{ARA}$ was fed at the start of the life cycle and at the initiation of the differentiation phase (Figs 1 and 2). A much smaller increase in $\left[1-{ }^{14} \mathrm{C}\right] 18: 1$ metabolites producing TEA salts was observed during differentiation when $\left[1-{ }^{14} \mathrm{C}\right] 18: 1$ was fed at the start of the life cycle (Table 2). These results cannot be explained at this stage and are being investigated. 


\section{Conclusions}

According to the results the following conclusions can be drawn.

Ungerminated ascospores contain about 18 times more lipids than germinated cell material. This lipid probably functions as an endogenous reserve material.

An increase in the percentage PUFA in the total lipid is observed in the phospholipid fraction during initiation of growth, followed by a sharp decrease, especially during the onset of differentiation. This is possibly associated with the predominance of phospholipid membranes in young growing cells requiring high degrees of fluidity.

The opposite is true for 18:1 - the percentage of this fatty acid increases in phospholipids during the differentiation phase.

Similar patterns of uptake were seen when $\left[{ }^{3} \mathrm{H}\right] \mathrm{ARA}$ and $\left[1-{ }^{14} \mathrm{C}\right] 18: 1$ were fed to $D$. uninucleata. There was rapid incorporation of both labelled ARA and 18:1 into phospholipids during the initial growth phase. However, during the differentiation phase, amounts of labelled ARA in the phospholipid fraction decreased abruptly but amounts of labelled 18:1 did not subsequently decrease. Thus there is a clear metabolic distinction between ARA, which is a PUFA and potential precursor of prostaglandin-type metabolites, and 18:1, which is presumably used wholly as a functional fatty acyl group in phospholipids and TAGs.

A much larger percentage of $\left[1-{ }^{14} \mathrm{C}\right] 18: 1$ is incorporated into TAGS at the end of the life cycle compared to $\left.{ }^{3} \mathrm{H}\right]$ ARA. This coincides with the change in relative amounts of 18:1 and PUFAs in neutral lipids during the life cycle of $D$. uninucleata. ARA is therefore not a preferred fatty acid for mobilization from the endogenous TAG reserves.

The loss of [ $\left.{ }^{3} \mathrm{H}\right] A R A$ from phospholipids during differentiation coincided with the appearance of labelled ARA metabolites capable of producing TEA salts. This was not observed in experiments using $\left[1-{ }^{14} \mathrm{C}\right] 18: 1$.

D. uninucleata clearly distinguishes between ARA and 18:1 and uses each for distinct functions. The role of
ARA as a precursor of prostaglandin-like materials continues to be investigated.

This work was supported by research grants from the FRD, South Africa, and the University of the Orange Free State, South Africa.

We thank Maureen Ewing and Marietjie Kock for their competent assistance during the investigation, Margaret Huffee for the Bioscan analyses and Leslie Galbraith from the Chemistry Department (University of Hull) for phospholipid and glycolipid analyses.

\section{References}

Botha, A., Kock, J. L. F., Coetzee, D. J., Linde, N. A. \& Van Dyk, M. S. (1992). Yeast eicosanoids II. The influence of non-steroidal anti-inflammatory drugs on the life cycle of Dipodascopsis. Systematic and Applied Microbiology 15, 155-160.

ButTe, W. (1983). Rapid method for the determination of fatty acid profiles from fats and oils using trimethylsulphonium hydroxide for transesterification. Journal of Chromatography 261, 142-145.

DitTMER, J. C. \& LeSter, L. (1964). A simple, specific spray for the detection of phospholipids on thin-layer chromatograms. Journal of Lipid Research 5, 126.

Folch, J., Lees, M. \& Sloane-Stanley, G. H. (1957). A simple method for the isolation and purification of total lipids from animal tissues. Journal of Biological Chemistry 226, 497-509.

HigGrNS, J. A. (1987). Separation and analysis of membrane lipid components. In Biological Membranes - a Practical Approach, pp. 103-137. Edited by J. B. C. Findlay \& W. H. Evans. Washington, DC: IRL Press.

Kendrick, A. J. \& Ratledge, C. (1992). Lipids of selected molds grown for production of $n-3$ and n-6 polyunsaturated fatty acids. Lipids 27, 15-20.

Kock, J. L. F., Coetzee, D. J., Van Dyk, M. S., Truscott, M., Cloete, F. C., Van WyK, V. \& Augustyn, O. P. H. (1991). Evidence for pharmacologically active prostaglandins in yeasts. South African Journal of Science 87, 73-76.

LAW, S. W. T. \& BURTON, D. N. (1976a). Lipid metabolism in Achlya: studies of lipid turnover during development. Canadian Journal of Microbiology 22, 1710-1715.

LAW, S. W. T. \& BURTON, D. N. (1976b). Lipid metabolism in Achlya: changes in lipid composition during development. Canadian Journal of Microbiology 22, 1716-1719.

Slater, T. F. \& MCDonald-Gibson, R. G. (1987). Introduction to the eicosanoids. In Prostaglandins and Related Substances - a Practical Approach, pp. 1-4. Edited by C. Benedetto, R. G. McDonaldGibson, S. Nigam \& T. F. Slater. Washington, DC: IRL Press.

Smith, J. D. \& Silverman, P. M. (1973). Lipid turnover during morphogenesis in the water mold Blastocladiella emersonii. Biochemical and Biophysical Research Communications 54, 1191-1197.

Van Dyk, M. S., Kock, J. L. F., Coetzee, D. J., Augustyn, O. P. H. \& NigAM, S. (1991). Isolation of a new aspirin-sensitive arachidonic acid metabolite 3-hydroxy-5,8,11,14-eicosatetraenoic acid from the yeast Dipodascopsis uninucleata UOFS-Y128. FEBS Letters 283, 195-198. 